\title{
Binarismo de gênero, identidade, trabalho e prostituição: um estudo qualitativo sobre a população transgênera de Belo Horizonte
}

\author{
Binarism, identity, labor and prostitution: a qualitative research on the \\ transgender population of Belo Horizonte, Brazil
}

\author{
Fabiana Bacelar Villani' ${ }^{1}$, Luiz Paulo Ribeiro² \\ 1Assistente social. Belo Horizonte, Minas Gerais, Brasil. ORCID: 0000-0001-8937-9253. fabianavillani@hotmail.com \\ ${ }^{2}$ Autor para correspondência. Universidade Federal de Minas Gerais. Belo Horizonte, Minas Gerais, Brasil. \\ ORCID: 0000-0002-4278-7871. luizribeiro@live.com
}

\begin{abstract}
RESUMO | OBJETIVO: Analisar a inclusão/exclusão do mercado de trabalho de pessoas transgêneras (travestis e transexuais) em Belo Horizonte. MÉTODO: Foram aplicadas nove entrevistas semiestruturadas a pessoas transgêneras residentes no município de Belo Horizonte/MG. A seleção foi feita de forma aleatória e de acordo com a disponibilidade dos sujeitos. Para a análise de dados foi feito o uso da análise de conteúdo categorial, que subdividiu o corpus de análise em quatro categorias. RESULTADOS: Os resultados apontaram que a inclusão/exclusão do mercado de trabalho nos sujeitos pesquisados estão organizados pelas categorias: (a) binarismo de gênero, sobre o processo de transição dos participantes; (b) documentação, sobre o reconhecimento oficial de identidade de gênero, o uso do nome social e as violências sofridas; (c) trabalho, demonstrando a relação dos sujeitos com as instâncias formais e informais de emprego e renda e (d) prostituição. CONCLUSÃO: A partir dos sujeitos participantes deste estudo pode-se indicar que população estudada encontra dificuldades para acesso ao mercado formal de trabalho e isso incide diretamente na perpetuação da exclusão social através da invisibilidade, aumento da informalidade, violência e não reconhecimento das identidades de gênero.
\end{abstract}

PALAVRAS-CHAVE: Transgênero. Trabalho. Identidade. Prostituição. Inclusão.

\begin{abstract}
OBJECTIVE: Verify the transgender people (transvestites and transsexuals) inclusion/exclusion in the Belo Horizonte's job market. METHODS: Nine semi-structured interviews were applied to transgender people residents in Belo Horizonte/MG. The selection was made randomly and according to the availability of the people. For the data analysis, the use of categorical content analysis was made, which subdivided the analysis corpus in four categories. RESULTS: The results indicate that job market inclusion/ exclusion of the interviewed people is organized by categories. a) gender binarism, about the participants transition process; b) documentation, about the official recognition of the gender identity, the use of social name and the violence suffered; c) work, demonstrating the relation of the people with the formal and informal instances of work and income and d) prostitution. CONCLUSION: From the participants of this study, it is possible to say that the studied population has difficulties to access the formal job market and this directly affects the perpetuation of social exclusion, through the invisibility, increased informality, violence and non-recognition of the gender identities.
\end{abstract}

KEYWORDS: Transgender. Labor. Identity. Prostitution. Inclusion. 


\section{Introdução}

A discussão sobre a exclusão da população transgênera do mercado de trabalho é algo corrente entre os sujeitos LGBT (Lésbicas, Gays, Bissexuais, Travestis e Transexuais etc.), porém ainda pouco explorada pelos estudos e pesquisas acadêmicas brasileiras, e, por isso é algo que merece aprofundamento, análise e intervenção psicossocial. Bento (2008) nos convida a refletir sobre uma situação hipotética: imaginemos que um importante funcionário do Estado brasileiro chegasse em seu ambiente de trabalho trajando um vestido, brincos, colares e outros adereços que nunca foram utilizados por ele. É bem provável que este episódio repercutiria em rumores, notícias e até mesmo na demissão deste sujeito. Em conformidade com Bento (2008), problematizando a trangeneridade frente à categoria trabalho há que se ter em mente que para a população transgênera a aparência ainda é um obstáculo no acesso ao mercado de trabalho formal.

Parte-se do pressuposto que um dos maiores motivos da exclusão é a inaceitabilidade por parte dos contratantes e da sociedade daqueles que fogem à norma padrão de gênero (cis-hetero-normativa) e suas expressões, sendo consideradas como pessoas que desviam ou transgridem o dispositivo binário de gênero (Lanz, 2014). Oliva (2015) diz que este padrão heterosexista induz a um discurso do ódio e a uma internalização de preconceitos. Sabe-se que o sistema binário de gênero, como propõe Bento (2006; 2008), é determinado pela natureza ao construir a sexualidade, posicionando os corpos de acordo com as disposições naturais e impõe que o gênero é o reflexo do sexo, bem como, todas as características que compõe os sujeitos. Isto quer dizer que, as únicas possibilidades no sistema binário de gênero são as configurações vaginas-mulheres-femininas e pênishomens-masculinos.

O gênero binário é observado quando se polarizam os corpos dentro das diversas áreas e saberes da sociedade, ou seja, pelos, seios e quadris são determinantes para identificar o que é ser homem e ser mulher. Butler (2017) ressalta que é essa construção/ estilização repetida do sexo/gênero que possibilita a existência dos corpos considerados abjetos já que esta repetição do gênero se dá dentro de uma estrutura reguladora altamente rígida criada para policiar a aparência social determinada dentro do sistema binário de gênero.
Como pontua Siqueira Peres (2012), quaisquer expressões que não correspondam às determinações do binário sexo/gênero tendem à abjeção que, nas palavras do autor, desapropria qualquer reconhecimento ou direito do sujeito, isto significa que, este sujeito não existe para a inteligibilidade normativa e por isso, é invisível e se é invisível, não é reconhecido como sujeito, portanto não existe e não pode ser considerado como um sujeito de direitos. Esta abjeção está relacionada "a todo tipo de corpos cujas vidas não são consideradas 'vidas' e cuja materialidade é entendida como 'não importante'"' (Butler, 2002, p. 161), ou seja, sujeitos cuja a vida não possuem importância social.

Diante da invisibilidade social e das violências decorrentes desta, a população travesti e transexual encontra dificuldades para ingresso e permanência no mercado de trabalho formal (Zanin, Ferreira \& Ribeiro, 2019) e nas políticas públicas - principalmente na escola (Ribeiro, Villani, Silva \& Alexandre, 2019). E diante disse questiona-se: $O$ que dizem os sujeitos transgêneros (travestis e transexuais) sobre os seus vínculos de trabalho na contemporaneidade? Existem violências? Dificuldades? Quais as implicações para a subjetividade e sociabilidade destes sujeitos?

Nogueira (2017) destaca que a maior parte da população transgênera encontra-se em situações precárias como miséria, exclusão social, falta de acesso à educação, saúde, qualificação profissional, oportunidade do mercado de trabalho formal e política públicas eficazes que atuem de acordo com a especificidade das demandas desta população. O não reconhecimento das identidades transgêneras, o abandono familiar, a evasão escolar, a precarização laboral, a exclusão do mercado de trabalho são fatores que contribuem com proliferação da violência e com a marginalização destes sujeitos. Para Oliva (2015), observando tal fenômeno social e histórico junto à população LGBTQIA+, cabe ao direito e, decorrentemente, do governo dos estados e países, facilitar a inclusão, reprimindo o ódio e co-construindo políticas afirmativas para as minorias sexuais e de gênero.

Ribeiro e Resende (2017) dizem que exclusão social e vulnerabilidade social se correlacionam intensamente, sendo que contextos em que há vulnerabilidade geram condutas excludentes e vice e versa. Neste sentido, a exclusão social pode ser entendida como um conjunto de processos que fortalecem a ruptura econômica, política e social, afasta e inferioriza as pessoas, os grupos, 
as comunidades e os territórios dos centros de poder, dos recursos e dos valores dominantes.

Diante disso, percebe-se que a falta de trabalho é um dos fatores centrais que podem desencadear a exclusão social e que o trabalho está diretamente interligado com as relações sociais, com a comunidade e com a família. Diz-se isso porque considera-se que é a partir do trabalho que o sujeito se constitui como ser social e eleva as suas capacidades humanogenéricas. E, dessa forma, a ausência de trabalho traz consequências econômicas e materiais que reforçam as desigualdades sociais.

Como afirmam Marx (1890-2017) e Antunes (1999), o trabalho é o que diferencia o homem dos outros seres da natureza, é ele que possibilita a autoconstrução de seu próprio processo histórico, a construção das relações sociais e a oportunidade de desenvolver as capacidades humano-genéricas: universalidade, sociabilidade, consciência e a liberdade. É o trabaIho que impulsiona o ser social, que dá origem às necessidades e às relações sociais mesmo que estas não sejam reduzidas ao trabalho. O trabalho também possibilita a busca por uma vida plena e origina novos complexos sociais como a moral, a ética, a religião, a ideologia, a filosofia, a arte, dentre outras (Lessa, 2015).

Assim, diante destes apontamentos, este estudo tem como objetivo analisar a inclusão/exclusão do mercado de trabalho de pessoas transgêneras (travestis e transexuais) em Belo Horizonte, tendo como hipótese que a exclusão da população transexual e travesti do mercado formal de trabalho é possivelmente motivada pela identidade de gênero destes sujeitos.

\section{Percurso metodológico}

Pautados nos estudos de gênero e trabalho, foram utilizados para embasar este estudo as contribuições de Carrieri, Souza e Aguiar (2013), Cisne (2004) e Hirata (2001). Esta pesquisa foi realizada na cidade de Belo Horizonte, no estado de Minas Gerais, Brasil. Segundo dados do Instituto Brasileiro de Geografia e Estatística estima-se que a população geral deste município seja de 2,5 milhões de pessoas, destes estima-se que de 0,6 a 2,8\% sejam transgêneros, ou seja um número entre 15 e 70 mil pessoas (Cunha \& Rios, 2006).
Foi escolhido o método de entrevistas semiestruturadas para coleta de dados. Manzini (2004) afirma que este tipo de entrevista faz uso de um roteiro previamente elaborado e ao longo do contato entrevistadorentrevistado é possível que surjam novos questionamentos complementares. Ela apresenta uma versatilidade e uma aplicabilidade em diferentes contextos e sujeitos, já que não necessita nível de escolaridade e, como de hábito, os sujeitos entrevistados tem alguma relação com o objeto pesquisado.

Foram entrevistados 09 sujeitos transgêneros. A busca por estes sujeitos foi feita de forma aleatória, não probabilística, intencional, tentando identificar pessoas que se autonomeavam como travestis, transexuais ou não-binários e, ao mesmo tempo, residiam em Belo Horizonte/MG e tinham interesse em participar do estudo. Os sujeitos convidados - inicialmente 30 sujeitos foram convidados - participaram da entrevista voluntariamente, ocorrendo inclusão no estudo somente por disponibilidade. Sabe-se que o número de sujeitos participantes já diz de uma das limitações deste estudo, que para generalizações seriam necessários mais sujeitos, porém alguns dos sujeitos convidados se negaram afirmando que as pesquisas acadêmicas pouco tem feito para a mudança da realidade social deles, ou ainda, por falta de tempo, ou por não estarem interessados em participar. Mesmo com poucos sujeitos decidiu-se continuar com o estudo, dando relevância aos relatos dos sujeitos que participaram, como sujeitos representantes qualitativamente de um grupo populacional.

Por finalidade ética, todos/as participantes assinaram os termos de consentimento livre e esclarecido (TCLE) e estão identificados/as nesta pesquisa através das letras do alfabeto escolhidas de modo aleatório. Esta pesquisa foi aprovada pelo comitê de ética em pesquisa e registrada sob o protocolo CAAE (protocolo em sigilo, vide arquivos suplementares à publicação).

Para a análise de dados foi utilizada a análise de conteúdo através de categorias proposta por Bardin (1977, p.37) que se concretiza em "tomar em consideração a totalidade de um "texto", passando-o pelo crivo da classificação e do recenseamento, segundo a frequência de presença (ou de ausência) de itens de sentido". Este processo de análise busca a construção de categorias de sentido diante das entrevistas e permite um olhar que compara as experiências de sujeitos diferentes em torno de um mesmo objeto de estudo. 


\section{Resultados e discussão}

A análise dos dados foi construída a partir da apresentação do conteúdo das falas dos sujeitos entrevistados organizadas a partir das categorias, sendo que cada uma delas foi interposta por literatura específica. Assim, para esta análise foram erigidas quatro categorias que estão interligadas à exclusão da população transgênera do mercado de trabalho, sendo a última categoria percebida como o resultado desta exclusão: 1) binarismo de gênero, 2) documentação e 3) trabalho e 4) prostituição. A seguir cada uma dessas categorias é analisada.

\section{Binarismo de Gênero}

Nos séculos XVIII e XIX, de acordo com Laqueur (2001), a mulher era considerada como uma imperfeição do homem, isto quer dizer que, não existia o sexo feminino. Para o autor, a sexualidade não era definida como masculina e feminina e sim como um modelo de sexo único. Este modelo consistia na existência de apenas um sexo uma vez que a mulher era a imperfeição do corpo do homem, ou seja, o útero era o escroto feminino, os ovários eram o testículos, a vulva era o prepúcio e a vagina era o pênis (Laqueur, 2001, p. 281).

Foi apenas através de dois momentos, um epistemológico e o outro político, que Laqueur (2001), destaca o surgimento do modelo de dois sexos, possibilitando a criação do sistema binário de gênero. A explicação epistemológica ocorre em duas explicações: a primeira é histórica em que distingue-se ficção, ciência da religião e a razão da credulidade. A segunda é explicada através da teoria foucaultiana pautada na episteme "no qual os sinais e as semelhanças eram entremeadas umas com as outras em uma espiral sem fim" (Laqueur, 2001, p. 191) em que as semeIhanças entre os corpos foram reduzidas hierarquicamente ao sexo.

Ainda para Laqueur (2001), as categorias "masculina" e "feminina" como sexo biológicos surgem apenas no final do século XVII e durante o século XVIII ancoradas inclusive através nos discursos feministas que rompiam com a ideia de que as mulheres eram a imperfeição dos homens. É somente a partir do modelo de dois sexos que se pode perceber o nascimento do binarismo de gênero, que nas palavras de Bento (2006) legitima apenas duas identidades que são necessariamente interligadas ao órgão genital; a identidade masculina e a identidade feminina e qualquer identidade divergente tais como transexuais, travestis, crossdressers, dragqueens são consideradas transgressoras (Lanz, 2014).

Parte-se do pressuposto que esta transgressão contribui para a exclusão do mercado de trabalho, é e necessário descontruir o sistema binário para a compreensão e a inclusão das diferentes formas de masculinidade e feminilidade. Bento (2008) chama a atenção ao destacar que as mulheres e homens que vivenciam feminilidades e masculinidades que fogem ao padrão hegemônico e que não são reconhecidas(os) e/ou legitimadas(os) como "verdadeiras/verdadeiros" fazem críticas aos sistema binário de gênero. A entrevistada $G$ diz sobre isso quando relatou:

Pelo fato da nossa estética não ser tida como estética normal por muitas vezes, porque quem geralmente é trans acaba aderindo a uma estética de acordo com o gênero e infelizmente é quase impossível que aquela pessoa alcance um padrão estético cisgênero, então é sempre tida como um projeto de mulher esquisita, um projeto de homem esquisito e mal acabado, então nunca é visto como pessoa normal. Não gosto desse termo passabilidade ${ }^{1}$ que é o que as pessoas geralmente tentam alcançar exatamente por isso. Eu acho que a estética tem que ser respeitada da forma que a pessoa é mesmo.

( $G$ - transfeminina não-binária-travesti, 26 anos).

Um dos métodos de alcançar esta adequação corporal imposta pela lógica binária é a possibilidade da cirurgia da redesignação sexual que é a "transformação plástico-reconstrutiva da genitália externa, interna e caracteres sexuais secundários [...] haja vista que tem propósito terapêutico específico de adequar a genitália ao sexo psíquico." (Conselho Federal de Medicina, 1997, s/p)

A cirurgia de redesignação sexual foi aprovada no Brasil através do Conselho Federal de Medicina CFM em Setembro de 1997 por meio da Resolução

'Passabilidade se refere a situação em que a identidade de gênero do sujeito 'passa' desapercebida nos locais de circulação, de sociabilidade etc. é uma capacidade de adaptação pessoal ao contexto social, ao mesmo tempo que é uma adaptabilidade que faz com que o outro não perceba a transgeneridade. 
1482/97 que permitia, a título experimental, esta cirurgia nos hospitais universitários. Também estavam subordinadas as intervenções às normas e diretrizes éticas da Resolução do Conselho Nacional de Saúde n¹961/1996 sobre pesquisas em seres humanos. Esta resolução foi substituída no ano de 2002 através da Resolução 1652/2002 que retirou o caráter experimental da cirurgia do tipo neocolpovulvoplastia e aderindo apenas o tipo neofaloplastia. Apesar destes avanços, foi apenas em 2013, de acordo com Rocon, Rodrigues e Sodré (2016), que o processo transexualizador do SUS 3 foi redefinido e ampliado através da Portaria 2803 que passou, então, a incluir as travestis e os homens transexuais no acesso aos serviços à saúde.

Entretanto criticando as normas impostas pela lógica binária, a entrevistada $\mathrm{A}$ se mostra contrária à cirurgia de redesignação sexual ao afirmar que:

Acho que pode até dar certo, mas a pessoa tem que estar muito preparada psicologicamente, tem que ter um acompanhamento muito bom, hoje em dia elas não tem esse acompanhamento, elas juntam um dinheiro $e$ vão operam e pronto, igual minha prima fez assim. Eu levei ela para a Itália em 2009, ela já foi na intenção de operar, juntou dinheiro, comprou apartamento, veio

para o Brasil, aí voltou, trabalhou, juntou dinheiro,

foi para a Tailândia e voltou toda operada, fez feminilização de rosto e tudo. Mas ela mesmo fala pra mim, se tem uma coisa que eu jamais faria de novo era isso, se eu pudesse voltar no tempo eu não faria de novo, ela mesmo fala. E eu tenho caso de várias amigas

também que estão sempre depressivas, sempre em depressão, então... Se uma pessoa fez uma cirurgia... se você fez uma cirurgia para procurar uma melhora ou se encontrar melhor, porquê que você vai entrar em depressão? Não é, verdade? Você tinha que ficar feliz, né. Eu acho que a mulher não está ali, está na cabeça, no espírito, no seu viver, no seu dia-a-dia, não é? Como você se enxerga, como você se vê, como você se comporta, como você age. A mulher não está ali própria no sexo, né. (A - mulher transexual, 54 anos).

Através da fala da entrevistada A, apesar do laudo psicológico após a decisão do Superior Tribunal Federal, ser recomendado e não mais obrigatório, compreende-se aqui a importância de se ter um acompanhamento psicológico junto à população transgênera para a realização da cirurgia de redesignação sexual. Bruns e Santos (2006) afirmam que é através da psicoterapia que se desencadeia o auto acolhimento a preparação para o recebimento da hormonioterapia com o intuito de realizar a cirurgia de redesignação sexual.

Expressando o mesmo desejo das entrevistadas anteriores, as entrevistadas $\mathrm{C}$ e $\mathrm{F}$ também não demonstram interesse em realizar a cirurgia de redesignação sexual pois:

Eu acho que eu nasci com, se deus me fez com um pênis, eu acho que... eu vou levar até o final. Eu não

tenho interesse, você sabe porque eu não tenho? Porque não é ele, não é genitália que vai mudar o que eu sinto pelo que é minha alma. (C - mulher transexual, 33 anos).

Não, não tenho, amo meu pinto, amo o que eu tenho entre as pernas até porque ele é meu ganha pão independente de ser meu ganha pão me identifico com o meu órgão sexual, sou uma mulher independente disso, se eu penetro ou não no homem isso não importa eu sou mulher eles me veem como "mulher" e eu aceito o que sou, sou feliz assim, quero morrer assim. ( $F$ - travesti, 34 anos).

Além da cirurgia de redesignação sexual, Galindo, Vilela e Moura (2012) também destacam a hormonioterapia que tem a função de produzir estéticas que performam na construção dos corpos e das formas e nas dinâmicas de subjetivação. Outras formas de performance são encontradas ao utilizarem apliques de cabelo, depilações, maquiagem, aplicação de silicone e cirurgias estéticas.

Percebe-se que, muitas vezes, o acesso a estes procedimentos é desigual, o que traz a entrevistada $\mathrm{G}$ a fazer uma crítica ao afirmar que:

É o corpo dela e ela tem direito, então a gente sabe que hormônio não faz mal, desde que seja controlado por um endócrino, mas como a gente não tem acesso

a endocrinologia e nem nenhum tipo de estado de saúde, as manas e os caras realmente se envolvem com hormonização clandestina, silicone industrial, que é um óleo de motor, tomam qualquer tipo de hormônio e tem elefantíase, trombose, AVC, derrame, porque não tem acesso. Então assim, se uma pessoa que tem fome não tem acesso a trabalho e comida, obviamente ela vai acabar roubando porque ela precisa daquilo para sobreviver e não que eu esteja fazendo comparação de fome a estar bem, mas é uma questão psicológica e político-social também, da mesma forma que uma pessoa quer adequar o corpo dela a uma estética que ela quer e ela não tem dinheiro pra aquilo, ela vai de uma forma se adequar, nem que seja de uma forma menos 
esteticamente bonita, e a questão trans é a mesma coisa. ( $G$ - transfeminina não-binária-travesti, 26 anos).

Com estes trechos pode-se verificar que apesar dos esforços da sociedade em impor a manutenção do binarismo de gênero, as cinco participantes estão em consenso ao defender que não possuem interesse em realizar a cirurgia de redesignação sexual porque aceitam seus corpos e não definem a sua identidade de gênero exclusivamente em função de suas genitálias. Isto significa que apesar de todas as imposições adotadas pelo modelo societário vigente, existe um movimento de resistência constituído por pessoas que entendem e aceitam seus corpos e defendem que não é o corpo que precisa se adequar à sociedade mas sim que a sociedade reconheça e inclua a corporalidade em toda a sua diversidade.

Em relação ao mercado de trabalho, essa categoria revela algumas facetas das cobranças do binarismo de gênero às pessoas transgêneras, principalmente no que se direciona à passabilidade. Se o/a sujeito/a não é percebido na sua identidade de gênero ele pode ser aceito nas instituições de trabalho formal, caso ele não atenda, ou demonstre qualquer disparidade, com o gênero a que se direciona, o vínculo trabalhista é dificultado ou quando ele existe é para trabalhos em posições subalternas, escondidas dos olhares dos consumidores, conforme aponta Irigaray (2012).

\section{Documentação}

A segunda categoria identificada nesta análise é a documentação na perspectiva da negação do uso do nome em concordância com a identidade de gênero bem como a utilização do nome social e o direito à mudança de nome e sexo em registro civil.

Por nome social, Jesus (2012) destaca que é o nome pelo qual as travestis e transexuais se identificam e preferem ser identificadas enquanto não há a retificação de registro civil. Sabe-se que o nome social reflete a expressão de gênero e contrapõe o nome de registro civil, este consonante com o gênero e/ou o sexo atribuídos durante a gestação e/ou o nascimento. No contexto dos participantes da pesquisa, alguns exemplos de que é possível a identificação da utilização do nome social são: nos registros escolares das escolas da Rede Municipal de Educação de Belo Horizonte, (2008), no Cartão SUS (em 2009), na Cédula e Carteira de Identidade Profissional do assistente social (em 2011), nas instituições de ensino (em
2015), no âmbito da administração pública federal (em 2016) e na educação básica (em 2018).

Em março de 2018, o Tribunal Superior Federal, por meio do julgamento da Ação Direta de Inconstitucionalidade (ADI) 4275, reconheceu o direito de transexuais substituírem o prenome e sexo no registro civil, independente da cirurgia de redesignação sexual. É através da retificação do prenome e do sexo no registro civil que se assegura o direito à dignidade da pessoa humana em sua completude possibilitando o desenvolvimento da sua personalidade. Neste estudo, os participantes destacam que a retificação de prenome e sexo no registro civil está relacionada à exclusão do mercado de trabalho conforme do entrevistado $D$ :

É, no caso, as mudanças físicas, assim, meio que vieram com o tratamento, né? Com endócrino, hormonal, e tal, as mudanças, no caso ainda tão acontecendo, né, porque eu preciso de retificar o nome, então eu não consigo emprego devido a eu não ter o nome retificado. [...] Já aconteceu comigo, eu tava com o nome social, fui entregar o currículo e tal, aí chegou lá... aí a pessoa foi e pediu meu $R G$, aí ela... acabou que eu entreguei o meu currículo com o nome social, só que na hora lá, no sistema deles, tava meu nome de registro, então, ou seja, se eu fosse contratado, já... meu currículo não ia valer de nada, né? ( $D$ - homem transexual, 24 anos).

Vergueiro (2015) classifica a passabilidade para determinar as vivências nas diversidades corporais e de identidades de gênero que se adequam às exigências cisnormativas como uma estratégia de resistência à violências cissexistas. O termo passabilidade cis, ainda segundo Vergueiro (2015) é a experimentação da invisibilidade contingencial por alguns gêneros divergentes do cisgênero, isto quer dizer que, enquanto há a passabilidade cis, os sujeitos desfrutam dos privilégios oferecidos por uma sociedade cissexista e transfóbica.

Outro fator que contribui para a exclusão da população transgênera do mercado de trabalho é a LGBTfobia instalada nos espaços educacionais. A Associação Brasileira de Lésbicas, Gays, Bissexuais, Travestis, Transexuais e Intersexos (ABGLT, 2016) realizou, no ano de 2016, uma pesquisa intitulada Pesquisa Nacional Sobre o Ambiente Educacional no Brasil que determina que o índice de evasão escolar é maior entre travestis e transexuais alcançando a marca de aproximadamente $73 \%$ desta população. Para 
a ABGLT (2016), a homo/lesbo/transfobia continua sendo um dos problemas nestes espaços bem como a negligência na formação para a convivência democrática com as diferenças individuais e coletivas. A pesquisa conclui que os espaços educacionais não são acolhedores ou seguros para os estudantes LGBT+ que permanecem prejudicados em seu desempenho acadêmico e evadindo da escola.

Sobre o mundo do trabalho, Zanin, Ferreira e Ribeiro (2019) apontam que pessoas LGBT tem dificuldades para encontrar emprego e se manter com um vínculo formal de trabalho. Entretanto, essa situação se atenua quando se trata da população transgênera, que nas instituições de trabalho tem relatos corriqueiros de dificuldades de reconhecimento de sua identidade, do nome social, além da violência cotidiana, isso é ressaltado por Geoffroy e Chamberland (2015), Carrieri, Souza e Aguiar (2014) e Irigaray (2012).

Conforme Ribeiro, Villani, Silva e Alexandre (2019) embora existam avanços quanto à população travesti e transexual alcançar espaços públicos, mídias sociais e televisivas no Brasil (IItaqui \& Felippi, 2017), o que tem se visto é que estatisticamente existem dados que indicam que o Brasil é o país que mais comete $o$ assassinato de pessoas transgêneras no mundo (Transgender Europe, 2017), algo que é paradoxal já que é o país que mais se busca conteúdo pornográfico de pessoas transgêneras (Rocha, Ban, \& Valenga, 2017). Há aí uma lógica de usos desses sujeitos, assim como uma situação que faz persistir as desigualdades e violências que essa população sofre.

Por outro lado, é perceptível que as travestis e a pessoas transexuais têm mais dificuldade em esconder suas diferenças do que os adolescentes gays e lésbicas, isto as levam a abandonar a escola e a não concluir os seus estudos, isso porque, para Bento (2011) a escola é uma instituição incapaz de lidar com a diferença e a pluralidade, é guardiã das normas de gênero e produz a heterossexualidade e por isso, as crianças deixam abandonam este ambiente considerado hostil. A autora critica o termo evasão em situações como essa pois observa que existe um desejo em eliminar e excluir as pessoas que contrapõe a sociedade binária de gênero, que segundo ela, "contaminam" o espaço escolar, ou seja, existe então um processo de "expulsão" e não de "evasão". Sobre isso as entrevistadas $\mathrm{G}$ e $\mathrm{H}$ apontam que:
Não tem como eu me matricular em qualquer escola, qualquer faculdade e eu sei, que por exemplo, eu não vou poder usar o banheiro que está de acordo com o meu gênero, eu sei que a escola não vai aceitar meu nome social. (G - transfeminina não-binária-travesti, 26 anos).

Por exemplo, eu fui uma vez numa boate aqui em Belo Horizonte, que tava eu e uma outra amiga minha e a gente ainda não... eu ainda não tomava hormônio, mas eu vestia como mulher, eu cheguei na bilheteria,

perguntei à moça se a gente podia entrar como... mulher. Ela falou que não, que a gente tinha que apresentar um documento comprovando que a gente era mulher. Infelizmente, isso aconteceu e isso acontece muito. ( $H$ - mulher transexual, 41 anos).

A partir destas falas dos entrevistados pode-se indicar que a negação do uso do nome social bem como a retificação de prenome e sexo no registro civil, podem contribuir para a exclusão da população transgênera do mercado de trabalho, bem como, dos espaços educacionais.

\section{Trabalho}

Esta categoria é central nas análises que se propõe este artigo, uma vez que o trabalho é elemento possibilitador da construção do ser social e das relações sociais. Na concepção de Marx (2017), o trabalho é um processo entre o homem e a natureza e é através desta ação que o homem é capaz de mediar, regular e controlar o metabolismo com a natureza. Quando o homem modifica a natureza externa, ele também é modificado por ela. Esta atividade ocorre com a ajuda dos meios de trabalho e opera uma transformação do objetivo de trabalho segundo uma finalidade que já estava concebida desde o início.

Lessa (2015) afirma que o trabalho é a protoforma do agir humano e que o trabalho é fundamental para a existência da atividade humano-social, ou seja, o trabalho é categoria fundante do ser social e possibilita a busca por uma vida plena que dá origem a novos complexos sociais tais como a moral, a ética, a religião, a ideologia, a filosofia, a arte e etc. Barroco (2009) traz que a sociabilidade e a universalidade são capacidades genéricas e são inerentes a todas as atividades humanas e permitem a reciprocidade social que implicam no reconhecimento mútuo de seres da mesma espécie que partilham de uma mesma atividade e que depende uns dos outros para viver. Além disso, para a autora, constituir-se cada vez mais socialmente significa dominar a natureza, criar novas 
alternativas, dar respostas sociais, resultando na transformação de todos os sentidos humanos.

Geoffroy e Chamberland (2015) apontam que é nas instituições de trabalho que as pessoas LGBT (por eles entendidas como minorias sexuais e de gênero) mais sofrem violências, principalmente microagressões que são difíceis de serem identificadas e punidas. Geoffroy e Chamberland (2015), apontam que no Canadá, Suíça, França, Bélgica e alguns dos estados dos EUA existem legislações trabalhistas que protegem os LGBTs contra a discriminação, muito embora essa legislação não elimine a existência de casos de violência, devido às microagressões.

Zanin, Ferreira e Ribeiro (2019) apontam em estudo recente na cidade de Belo Horizonte que quase metade dos LGBTs que tentaram emprego não o conseguiram, $21 \%$ das situações de não consecução de entrada no mercado de trabalho formal, afirmado pelos sujeitos participantes da pesquisa, foi decorrente da orientação sexual ou identidade de gênero. Destes, um terço dos que encontraram problemas são pessoas transgêneras (travestis e transexuais). As pessoas transgêneras encontram dificuldades, muitas das vezes por não serem sujeitos com passabilidade. A entrevistada $\mathrm{H}$ destaca que a exclusão do trabalho traz consequências como o sentimento de rejeição e exclui a participação desta população na sociedade ao refletir que:

Quando se fala que você é uma trans e que você é um travesti, eles, a sociedade em si tem na cabeça que ou trabalha em salão, ou faz programa. E não é verdade. Eu tô falando da classe social trans e travesti.

Pra gente é muito difícil cê ver um... uma amiga, cê ver uma companheira de... de dia a dia, uma pessoa que frequenta a sua casa, chegar pra você e falar

comigo assim... falar com você que foi rejeitada porque você é uma trans, foi rejeitada porque nos seus documento você é um menino, ou foi rejeitada porque eu não tenho como provar que eu sou uma travesti. Então, é muito difícil. Então, eu queria que esse trabalho que vocês tão fazendo, essa entrevista que cês tão fazendo, que isso se expandisse mais pra sociedade, pra sociedade enxergar que nós trans e nós travestis, também somos seres humanos, nós queremos trabalhar, nós queremos ter vida na sociedade e a gente não tem. Principalmente na área de trabalho. ( $H$ - mulher transexual, 41 anos).
A entrevistada A relatou que, apesar de trabalharem, independentemente do tipo de vínculo formal ou informal, também é comum que a pessoas transgêneras sejam impedidas de exercer a sociabilidade e a universalidade uma vez que:

Eles colocam a gente lá no fundo, ou para atender um telefone, em um lugar onde o povo escuta sua voz mas não vê sua cara, entendeu? Você pode questionar isso, observar isso para você ver, eu sou muito observadora.

Trabalho eles dão, mas você não pode expor sua cara. Você já viu alguma trans vendedora em uma loja de shopping ou alguma coisa? Não tem. Em São Paulo eu conheço várias que trabalham em shopping, em São Paulo, mas aqui em Belo Horizonte não tem.

Ah, estão abrindo vaga, mas é para você ficar lá no fundo, escondidinha. Isso pra mim é um preconceito!

Não, é? E uma bobeira do pessoal... porque as

transexuais, nós, eu mesma sou uma pessoa muito alegre, muita comunicativa, se fosse para trabalhar em um comércio eu ia fazer milhões de clientes, porque eu sou uma pessoa hipercomunicativa, superalegre, uma alegria assim... Eu conquisto uma pessoa assim, espontaneamente, tenho muita facilidade de estar com as pessoas, fazer amizade. Eles tinham que olhar tudo isso, entendeu, eu sou muito carismática, mas eles não olham esse espaço, eles colocam a gente lá no ..., você trabalha nos bastidores, no fundo, na frente ninguém coloca, nunca vi. (A - mulher transexual, 54 anos).

Sobre as limitações no mercado de trabalho, a entrevistada $\mathrm{G}$ também expõe que a exclusão começa antes da entrevista quando a documentação não está em conformidade com a identidade de gênero binária. Ela problematiza que o desrespeito ao nome social e às diversas identidades de gênero, como por exemplo, a não binária traz consequências psicossociais para a população transgênera.

Então assim, a empregabilidade ela é muito limitada a partir desse ponto que a gente não tem oportunidade nem de chegar a entrevista, quando chega na entrevista a pessoa quer me tratar pelo nome de registro quando eu chego na entrevista e falo que sou pessoa nãobinária, tem apenas a opção feminino e masculina, e se eu não me encaixar em nenhuma das duas? sabe? Como é que eu vou conseguir trabalhar numa empresa onde eu vou ter que atender e dizer que eu sou homem, me apresentar como homem e falar meu nome de registro? Sabe? Não tem a menor condição isso fode a cabeça de qualquer pessoa e eles não tão nem aí. Se adequa a isso daqui ou tu realmente não tem 
emprego e acaba caindo toda população trans, a grande maioria, mais de $90 \%$ na prostituição.

( $G$ - transfeminina não-binária-travesti, 26 anos).

Por outro lado, a entrevistada B destaca que o trabaIho foi uma das formas que possibilitou o seu reconhecimento enquanto parte da comunidade em que mora fazendo com que ela não precisasse recorrer à marginalidade:

Eu sou uma pessoa reconhecida no meu bairro, eu tenho o meu trabalho, eu moro com a minha família,

isso assim... eu posso dizer seguramente que isso assim... é 1\% da classe trans. Nós somos a minoria, da minoria, da minoria, geralmente a trans, ela... primeiramente... ela não tem... é... oportunidade de emprego. Primeiramente ela nem estudou, porque ela não teve condições, no colégio é quase impossível você estudar, né, a minoria peita... e... estuda da maneira... na medida do possível, pouquíssimas formam, tudo é

$1 \%$ no público trans, nessa classe trans, né, e... então assim, é... primeiramente no colégio, depois no... no... no... trabalho é muito pouco, então assim.

A entrevistada B também reconhece que o apoio da família foi essencial para que ela tivesse acesso à educação, à sociabilidade e não caísse nas margens da marginalização, fazendo com que esta entrevistada sinta-se privilegiada em relação às outras vivências de pessoas transexuais e travestis.

Eu tenho um amigo meu que fala assim "Olha Leandra, você é uma pessoa que ganhou na loteria, assim" E eu falo que é verdade, sabe, porque assim... até então... é... você... é... ter uma... é... ser criada em uma família, ter né.... ter tido uma educação assim, bacana, você ter um caráter bacana, ser uma pessoa honesta. Você pode ver que a maioria já cresce dentro de um ambiente com distúrbio, então a maioria tem maus costumes, de todos os... possíveis e impossíveis, a maioria usa drogas, a maioria cai na marginalidade, né, então isso tudo com o passar do tempo vai... vai deixando a pessoa... é... esculhambada, digamos assim. Fica uma pessoa assim... quase que insociável, então assim... eu,

graças a deus, eu me sinto muito privilegiada por ser trans e por ter alcançado todos os objetivos que eu quis até hoje. (B - mulher transexual, 30 anos.)

As entrevistadas desta pesquisa também elucidaram alternativas para as empresas bem como para a sociedade para realizarem a inclusão da população transgênera no mercado de trabalho. Estas alternativas perpassam por incentivos fiscais, adoção do uso do nome social bem como inclusão das identidades de gênero não binárias no reconhecimento das identidades de gênero dentro das empresas, políticas afirmativas de cotas e até o oferecimento de bolsas de estudos para incentivar a formação destas pessoas.

Correlacionando com a outra categoria, sobre a documentação, o uso do nome social e inclusão das diversas identidades de gênero dentro das empresas, a entrevistada $D$ reflete que:

A respeito do emprego, deveria expandir pras... as empresas também ter acesso à contratação dessas pessoas trans, porque muitas pessoas trans, elas têm interesse de trabalhar e tal, mas elas não conseguem emprego... muitas vezes... às vezes, até por preconceito, às vezes, a própria empresa não sabe como que faz a respeito da documentação. (D - homem transexual, 24 anos).

Por sua vez, a entrevistada E aborda que a inclusão do mercado de trabalho poderia acontecer através de uma parceria do governo com as empresas por meio de incentivos:

Ainda o mercado de trabalho isso é uma coisa que nossa...me incomoda muito, uma coisa que eu acredito que podia é...melhorar é...o incentivo do governo, junto com empresas, para a inserção de pessoas trans no mercado de trabalho, isso é uma coisa que tipo assim, não tem , não tem de forma alguma e...e a pessoa trans sofre no mercado de trabalho porque não abrem as portas para uma pessoa trans. [....] Nem que o governo crie uma cota para essas...essas empresas, para essas empresas, sabe? Algum tipo de incentivo para as empresas, para tipo assim querer contratar nem que seja obrigado, a tipo assim ah se vocês contratarem uma pessoa trans você tem $30 \%$ de desconto na conta de luz, sabe? Nem que seja uma obrigação, sabe? Para

ter pessoas, porque querendo ou não essas pessoas tem que ser inseridas no mercado de trabalho, porque

se não a prostituição só vai aumentar porque para onde que eu corro? Para onde que eu vou? ( $E$ - mulher transexual, 23 anos).

Para a entrevistada $F$, esta inclusão seria adotada através da educação por meio da oferta de bolsas de estudo que contribuiria para a retirada desta população da prostituição: 
É que as pessoas se solidarizem com nós trans e pare de ver nós como marginal e o principal de tudo, se pudesse em Belo Horizonte, porque em São Paulo já tem, tem o bolsa trans, bolsa travesti para aumentar a autoestima das meninas pra voltar e a estudar sair da prostituição ter uma, um emprego, dar algum, sei

lá projeto social que dá emprego pra nós quando a gente sair da escola em São Paulo já tem isso, né? Elas

recebem para estudar, se faltar um dia de aula eles não dão o dinheiro para as meninas e o principal tirar

a gente da prostituição, da marginalidade né? Uma travesti precisa principalmente é de um emprego.

( $F$ - travesti, 34 anos).

As entrevistadas também deram exemplos de instituições educacionais que já realizam estas atividades por meio do incentivo à formação da população trans e travesti em Belo Horizonte, é o caso da TRANSVEST e o TransENEM, com cursos preparatórios para ingresso no ensino superior.

Apesar da escassez das ofertas de trabalho para a população transgênera, a entrevistada $\mathrm{G}$ destaca estabelecimentos - principalmente bares e casas de show - que empregam com uma proposta inclusiva. Entretanto, ela afirma que nas grandes empresas, em empregos "comuns", ainda há dificuldade de inserção.

Não há emprego para pessoas trans em $\mathrm{BH}$ a gente tem pouquíssimos grupos que por exemplo entre aspas no edifício maleta tem um restaurante, um bar chamado olimpia, eles tem algumas vagas voltadas para pessoas trans, tem alguma coisinha aqui, outra ali , mas a gente nunca tem por exemplo um emprego comum numa loja

$C . . ., R$..., R... [entrevistada cita lojas de departamento], a gente não consegue realmente.

(G - transfeminina não-binária-travesti, 26 anos).

Através da análise desta categoria, compreende-se que a negação do trabalho afeta a possibilidade da construção do ser social e contribui para a exclusão das pessoas transexuais e travestis de participar da vida social, empurrando-as para ocupar às margens mais distantes da sociedade. Se por um lado há exclusão, como demonstrado, por outro, em que há a inserção no mercado de trabalho pode-se verificar que este vínculo também é precário. Trabalhar escondida, trabalhar em ambientes "alternativos", "na noite" são propostas que não tiram as pessoas transgêneros da vulnerabilidade social. Há que se problematizar ainda que muitas empresas adotam mercadologicamente ações em prol da inclusão da diversidade (Zanin, Ferreira \& Ribeiro, 2019), algumas ainda a fazem de forma a colocar tais sujeitos fora da circulação na empresa ou em postos de trabalho em que devem ocultar suas identidades (Heloani e Capitão, 2012).

\section{Prostituição}

A última categoria desta análise é a prostituição que nesta presente pesquisa será entendida como um efeito da exclusão do mercado de trabalho. A exclusão do mercado de trabalho formal pode gerar consequências como a busca pela prostituição, que segundo Pelúcio (2005) pode ser entendida de três formas: a primeira como uma atividade sem prestígio realizada momentaneamente até que se encontre uma alternativa para abandoná-la assim que possível, a segunda como uma forma de ascensão social, econômica e de obter conquistas materiais e simbólicas e a terceira sendo uma forma que gera trabalho e cria um ambiente de sociabilidade.

Dados da Associação Nacional de Travestis e Transexuais (ANTRA) (s/d) afirmam que $90 \%$ da população transgênera encontra-se em situação de prostituição e podem ser consideradas algumas das causas para estes dados, de acordo com Nogueira e Leon (2012) a exclusão do mercado de trabalho e o preconceito enquanto que Ferreira, Pereira e Amaral (2010) pontuam que a prostituição pode ser considerada uma das expressões da questão social na sociedade capitalista.

Piscitelli (2008) descreve que o debate sobre prostituição é complexo e possui duas perspectivas políticas que são discutidas dento do movimento feminista: a primeira perspectiva entende a prostituição como violência e negação dos direitos humanos das mulheres, estas que são identificadas como vítimas das condições de desigualdade e exploração, que vivem para servir os homens, legitimando, dessa forma, a ordem sexista e patriarcal em que a mulher se torna propriedade daquele homem que a paga. A segunda perspectiva vincula a prostituição com a fonte maior do poder, de autonomia, de ameaça ao sistema patriarcal.

Apesar das duas perspectivas, Piscitelli (2008) chama a atenção para a prostituição sob a lógica de negócio em que as mulheres utilizam o próprio corpo como um "meio de sobrevivência dissociado de qualquer compreensão de subversão e/ou separação da ordem capitalista-patriarcal" (p.14). A entrevistada E declara que existem duas alternativas para a população 
transgênera se manter: a prostituição ou qualquer função que ela possa realizar de forma autônoma sem necessitar da sociedade ou do governo. Nas palavras da entrevistada:

Bom, é. depois que eu assumi minha transexualidade, o impacto pior foi na sociedade. É... esse tipo assim, o mais difícil pra uma pessoa trans é encarar o mundo aqui fora, porque... o mercado de trabalho não te aceita, é... todo mundo tipo assim... tipo assim... Cê não tem nenhum apoio, cê não tem nenhum tipo assim, ninguém tá nem aí procê, sabe? "Ah, se vira" ou... a pessoa trans ou ela se prostitui, ou vira é... cabeleireiro, que aí sim é uma coisa que vai depender só dela, se for uma coisa que vai depender do governo, da sociedade, é uma coisa que tipo assim, ainda é muito difícil, as pessoas, da sociedade ainda não aceitam. [...] Eu já conversei com meninas que são prostitutas, são pessoas, meninas trans, prostitutas mas que nunca escolheu aquilo. Teve que ir porque tipo assim, não, mas porque tipo assim eu cheguei a perguntar: "mas por que? Cê quis isso?" Ela não soube responder uai, tipo "que que eu vou fazer? que que eu

ia fazer? minha opção foi essa" tipo assim o governo não te dá outra opção, sabe? Se você é trans cê não tem outra opção a não ser: ou cê vai pra rua ou cê vai pra mexer com cabelo, fazer unha, qualquer coisa que não precisa de um empregador ou do governo, sabe?

É triste.

(E - mulher transexual, 23 anos).

Sobre a prostituição como alternativa à exclusão do mercado de trabalho, a entrevistada $F$ também chama a atenção para outra situação: a marginalização da população transgênera, que pode ainda, encontrar na criminalidade outra alternativa de sobrevivência ao salientar que:

A partir do momento que eu sou, né me assumi travesti todas as portas se fecharam em todos os sentidos procurar emprego e isso é normal na sociedade, aí já fui jogada para a marginalidade não segui o mundo do crime como a sociedade queria que eu seguisse graças a Deus, e fui no caminho contrário que é a prostituição.

( $F$ - travesti, 34 anos).

Jesus (2012) afirma que a população transgênera é estigmatizada e perseguida historicamente devido a sua identidade de gênero divergir do que foi determinado durante o nascimento, o que é considerado anormal para a sociedade cis-hetero-normativa. Este estigma faz com que esta população, principalmente, as travestis, sejam excluídas do trabalho mesmo que sejam qualificadas e destaca que as travestis também são, em grande parte, excluídas das escolas, do mercado de trabalho formal fazendo com que sobrevivam na marginalidade e em situação de prostituição.

Em contrapartida, a prostituição além de ser considerada uma alternativa para a sobrevivência também é uma das formas de socialização, conforme aborda Brito-Silva (2013, p.5) ao elucidar que as prostitutas "aprendem, trabalham, articulam-se, entram e mediam conflitos, e exercem ali outros papéis e atividades sociais". Dentre estas atividades sociais estão o comércio informal de roupas e maquiagem, a medicação com a polícia, a participação da criação compartilhada dos filhos e estão presentes em momentos de adoecimentos ou celebrações e, também, participam dos processos de saúde-doença-cuidado.

Brito-Silva (2013) também ressalta que prostituição e os locais em que ela ocorre, se apresentam como um novo espaço de vida e de trabalho que apesar de todas as adversidades e contradições, constituem a subjetividade das prostitutas e as inscrevem no mundo, possibilitam o sentimento de pertencimento a um lugar e criando as relações. Para a autora, a prostituição "é constituída de elementos agregativos, de uma rede de sociabilidade, compartilhamentos e pertencimento ao grupo, ao lugar (p.8). Corroborando com a fala de Brito-Silva (2013), a entrevistada H observa que é na prostituição que as travestis socializam ao revelar que:

Olha, não é fácil, todo mundo sabe que não é fácil, principalmente pras travestis que fazem programa e trabalham à noite, que eu tenho muitas amigas que trabalham à noite, outras trabalham em salão, que eu acho que é a única área que todo mundo socializa,

é..o mundo travesti. ( $H$ - mulher transexual, 41 anos).

A partir desta categoria de análise, entende-se que a prostituição, apesar de ser uma profissão não regulamentada e que oferece riscos, é a alternativa adotada pela população transgênera como meio de sobrevivência e como uma forma de exercer a sociabilidade que permite com que as pessoas em situação de prostituição conheçam o sentimento de pertencimento que lhes é negado dentro de uma sociedade binária e conservadora.

De acordo com as ideias de Kuenzer (2007), os grupos periféricos compõe o que a autora denomina como exclusão includente, ou seja, são trabalhadores que são facilmente encontrados no mercado de trabalho, 
que apresentam baixa qualificação e alta rotatividade e são incluídos em ocupações precarizadas. Este processo, ainda de acordo com Kuenzer (2007), exclui para incluir os sujeitos em subempregos perpassando pela inclusão excludente que também acontece nas escolas que ao oferecerem propostas desiguais e diferenciadas de educação, contribuem para a produção e justificativa da exclusão.

\section{Considerações finais}

Ela servia cafés todos os dias naquele mesmo edifício no centro do Belo Horizonte. Recebia muitas cantadas dos homens casados que passavam por ali e sempre faziam os mesmos pedidos. Muito embora fossem desrespeitosas essas micro agressões a faziam se sentir mulher desejada, algo que a tocava e enternecia diante de tantas passagens para se 'parecer' mais feminina, mais doce, mais mulher. Ela não avançava diante dos pedidos, não se envolvia com os clientes do estabelecimento, mas sentia que guardava um segredo por ser transexual, uma 'mulher de pau'. Enquanto escondia seu segredo estava protegida da violência que assola os demais sujeitos que estão em mesma condição.

Porém, do outro lado da rua, travestis e transexuais que recorrem à prostituição como alternativa ao trabalho, estão expostas às mais diversas violências tais como a violência física, psicológica, sexual, patrimonial, moral, de gênero, institucional, dentre outras. Estas violências podem ser praticadas por policiais, michês, clientes e pela disputa pelo "ponto de prostituição". Travestis e transexuais que recorrem tanto à prostituição ou aos empregos formais e informais, buscam atingir a passabilidade como um mecanismo de proteção, violência e como indicador de sucesso em seu processo de feminização. A passabilidade é o reconhecimento social do gênero feminino, ou seja, uma mulher transexual se torna passável ao ser reconhecida por outrem por pronomes de tratamento no feminino - esta nominação também pode ser aplicada para outros contextos, como para homens trans, travestis etc.

A passabilidade é a responsável por fazer com que as pessoas transexuais sigam os mesmos os modelos corporais e padrões de beleza que as pessoas cisgêneras, deixando à margem aqueles sujeitos que desafiam as estruturas binárias de gênero. Passar está relacionado diretamente com o investimento financeiro envolvido segregando as pessoas transexuais que possuem maiores condições de pagar por uma passabilidade alta enquanto que as de menor ou sem condições de pagar continuam não sendo dignas de respeito.

Concorda-se que a temática mercado de trabalho tem se tornado relevante socialmente já que através das pesquisas aqui elencadas apontam dificuldades vivenciadas por não heterossexuais tanto no mundo do trabalho quanto nas organizações. Nestes ambientes ainda encontram-se violência, assédio moral e sexual e a prática de estereotipar os sujeitos em relação às suas carreiras.

Talvez a aceitação social possa garantir o tratamento igual de condições entre as travestis e qualquer outra pessoa igualmente qualificada em entrevistas de emprego e exercício de atividades profissionais. Mas indo em direção contrária, as estratégias para a obtenção de emprego ou trabalho adotadas pelas travestis são: influências de amigos, referências de antigos empregadores e associações entre amigas. Já as estratégias para enfrentar dificuldades vão desde a insegurança, o receio de chamar atenção, temores com relação aos preconceitos, necessidade de afirmação profissional e pessoal, receio de acomodação e receio de ter que abrir mão das mudanças na aparência física.

Nota-se que a busca pelo trabalho formal é mais difícil para as travestis uma vez que estas são consideradas seres abjetos e por isso, são mais vulneráveis às violências interpessoais. Por não buscarem encaixes ou ajustamentos dentro do sistema binário de gênero, as travestis estão mais sujeitas à atos de violência interpessoal porque passam a ser consideradas e vistas como não humanas e tratadas como objetos.

Retoma-se que Carrieri, Souza e Aguiar (2014) evidenciam que existem dois tipos de violências que a comunidade LGBT (Lésbicas, Gays, Bissexuais, Travestis e Transexuais) vivenciam no mercado de trabalho: a violência simbólica e a violência interpessoal. A violência simbólica ocorre, de acordo com os autores, quando os sujeitos gênero-divergentes do padrão cis-hetero-normativo são coagidos e obrigados a se ajustarem naquilo que é considerado normal. Este tipo de violência acontece através do reforço de pensamentos que estão alinhados às estruturas vigentes impostas. A violência simbólica para as pessoas transexuais é instaurada pelo corpo quando o sistema binário de gênero obriga estes sujeitos a adequarem 
seus corpos ao padrão de corpos para homens e muIheres uma vez que não em um sistema binário de gênero, não são vislumbrados outras alternativas de corporalidade. Isto significa que, também de acordo com os autores, é pela naturalização do binarismo de gênero que a violência simbólica atua sobre as pessoas transgêneras. Por outro lado, a violência simbólica é percebida entre as travestis quando, ao não sentirem necessidade a se adequarem ao sistema binário de gênero, estas passam a ter seus corpos considerados abjetos.

Outro tipo de violência que acomete esta população é a violência interpessoal, que se manifesta em forma de agressão física ou discursiva bem como por meio de intimidações, comportamento vexatório, ameaça, assédio, comentários, ações e/ou gestos hostis e indesejados que afetam a dignidade e/ou a integridade psicológica. A partir das nossas análises consideramos que a primeira violência que as travestis sofrem é pelo fato de não serem tratadas com humanidade, ou seja, quando procuram trabalho, elas não são consideradas como recurso humano para o trabalho. A violência interpessoal chega ao seu nível máximo quando ocorrem manifestações de agressões físicas graves contra as travestis. Também para os autores, as pessoas transexuais experimentam a violência interpessoal através do antagonismo nos documentos de identificação versus a corporalidade apresentada que os tira da invisibilidade e denuncia a condição transexual como algo anormal.

Pode-se constatar que o grande capital financeiro possibilita o desemprego, a exclusão ou a não reinserção no mercado de trabalho, o descumprimento das responsabilidades públicas no âmbito dos serviços e direitos sociais por parte do Estado que consequentemente contribuem para o aumento da pobreza e da miséria e comprometem os direitos sociais, humanos e ferem o direito à vida. Dessa forma vislumbra-se que existe uma dupla exclusão quando pensamos na população trans e travesti. A primeira quando entende-se a relação do modo de produção capitalista versus mercado de trabalho e a segunda ao relacionar a exclusão desta população exclusivamente em função de sua identidade de gênero visto que esta população já está inserida em uma sociedade que segue o modelo de produção capitalista que, por si só, já é excludente.
Deste modo, esta pesquisa se propôs a analisar a centralidade do trabalho para a sujeitos transgêneros na cidade de Belo Horizonte, a partir da análise da inserção/exclusão de nove pessoas de gênero-divergente ao cis-hetero-normativo ao mercado de trabalho. É possível perceber que a partir dos sujeitos entrevistados que existe um desejo por exercer trabalho formal, não só em função de seu sustento mas também como uma forma de sociabilidade e alcançar respeito nas comunidades em que vivem. Mesmo assim, é possível questionar se este desejo de inclusão pelo trabalho persiste em toda a população transgênera da localidade estudada e de todo o país, uma vez que a pesquisa aqui executada possui suas limitações por ter sido feita apenas com nove sujeitos. Dessa forma, para pesquisas futuras há a sugestão de tentativa da participação de mais sujeitos e de outras localidades para o entendimento de um retrato regional e nacional sobre o mercado de trabalho para estes sujeitos.

Entretanto, sabe-se que muitos são os impasses para a contratação que permeiam o despreparo das empresas bem como dos recursos humanos, a evasão escolar que tiram estes sujeitos da alta competitividade no mercado de trabalho e fatores como a falta de apoiar no seio familiar que geram consequências como a marginalização.

Outro fator importante da negação do trabalho para estas pessoas é a prostituição encarada como única alternativa de sobrevivência, que apesar de garantir um sentimento e local de pertencimento nas ruas e pistas também traz diversos perigos tais como homicídios, roubos, agressões e contração infecções sexualmente transmissíveis.

\section{Contribuições dos autores}

Villani, F. B. foi bolsista de iniciação científica, responsável pela estruturação teórica, coleta e análise de dados da pesquisa. Atuou na escrita direta do artigo em questão. Ribeiro, L. P. foi orientador da pesquisa de iniciação científica, responsável pela escrita geral do projeto e submissão no coep, foi responsável além das condutas de orientação de pesquisa pelo auxílio teórico, no tratamento dos dados e na análise dos mesmos. Atuou na escrita direta do artigo e em sua revisão. 


\section{Conflitos de interesses}

Nenhum conflito financeiro, legal ou político envolvendo terceiros (governo, empresas e fundações privadas, etc.) Foi declarado para nenhum aspecto do trabalho submetido (incluindo mas não limitando-se a subvenções e financiamentos, participação em conselho consultivo, desenho de estudo, preparação de manuscrito, análise estatística, etc.).

\section{Referências}

$A D / 4275$. Reconhece o direito dos transexuais, que assim desejarem, à substituição de prenome e sexo no registro civil, independentemente da cirurgia de transgenitalização. Recuperado de: http://www.stf.jus.br/portal/geral/verPdfPaginado. asp?id=400211\&tipo=TP\&descricao=ADI\%2F4275

Antunes, R. L. C. (1999). Os sentidos do trabalho: ensaio sobre a afirmação e a negação do trabalho. Perdizes: Boitempo.

Associação Brasileira de Lésbicas, Gays, Bissexuais, Travestis e Transexuais. (2016). Secretaria de Educação. Pesquisa Nacional sobre o Ambiente Educacional no Brasil 2015: as experiências de adolescentes e jovens lésbicas, gays, bissexuais, travestis e transexuais em nossos ambientes educacionais. Curitiba: ABGLT.

Associação Nacional de Travestis e Transexuais (2017). Assassinatos de Pessoas Trans [Internet]. Recuperado de https:// www.google.com/maps/d/viewer?mid=1yMKNg31SYjDASON-ZwH1jJOapFQ\&hl=en_US\&II=-17.152191563664402\%2C-51.334074999999984\&z=4

Bardin, L. (1977). Análise de conteúdo. Lisboa: Edições 70.

Barroco, M. L. S. (2009). Ética: fundamentos sócio-históricos (2a ed.). São Paulo: Cortez.

Bento, B. (2006). A reinvenção do corpo: sexualidade e gênero na experiência transexual. Rio de Janeiro: Garamond.

Bento, B. (2008). O que é transexualidade. São Paulo: Brasilience.

Butler, J. (2017). Problemas de gênero: feminismo e subversão da identidade (13a ed.). Rio de Janeiro: Civilização Brasileira.

Carrieri, A. P., Souza, E. M., \& Aguiar, A. R. C. (2014). Trabalho, violência e sexualidade: estudo de lésbicas, travestis e transexuais. Revista de Administração Contemporânea, 18(1):78-95. Recuperado de http://www.scielo.br/pdf/rac/ v18n1/a06v18n1.pdf

Cisne, M. (2004). Serviço social: uma profissão de mulheres para mulheres? Uma análise crítica da categoria gênero na história da "feminização" da profissão (Dissertação de mestrado). Universidade Federal de Pernambuco, Recife, PE, Brasil. Recuperado de https://repositorio.ufpe.br/ handle/123456789/9916
Cunha, L. R., Rios, V. C. (2016). Mercado transgênero e a dignidade da pessoa humana sob perspectiva do capitalismo humanista. Revista dos tribunais, 972. Recuperado de http:// www.mpsp.mp.br/portal/page/portal/documentacao_e_divulgacao/doc_biblioteca/bibli_servicos_produtos/bibli_boletim/bibli_bol_2006/RTrib_n.972.09.PDF

Ferreira, I. B., Pereira, M. C., \& Amaral, S. G. P. (s/d). Prostituição: opção ou determinação social? (Pesquisa de Iniciação Científica). Pontifícia Universidade Católica de São Paulo PUC-SP, São Paulo, Brasil.

Galindo, D., Rodrigues R. V., \& Moura, M. (2012). Uma dose queer: performances tecnofarmacológicas no uso informal de hormônios entre travestis. In: L. L. Souza, D. Galindo, \& V. Bertoline. (Orgs.). Gêneros, Corpos e @tivismos (pp.171197). Cuiabá, MT: Editora da Universidade Federal do Mato Grosso.

Heloani, J. R., \& Capitão, C. G. (2012). Sexualidade e trabalho na visão da psicanálise. In M. E. Freitas, \& M. Dantas (Orgs.). Diversidade Sexual e trabalho (pp. 23-49). São Paulo: Cengage Learning.

Hirata, H. (2001). Globalização e divisão sexual do trabalho. Cadernos Pagu,(17/18): 139-156. Recuperado de http://www. scielo.br/pdf/cpa/n17-18/n17a06.pdf. doi: 10.1590/S0104$\underline{83332002000100006}$

Irigaray, H. A. R.. (2012). Travestis e transexuais no mundo do trabalho. In M. E. Freitas, \& M. Dantas (Orgs.). Diversidade sexual e trabalho (pp. 121-147). São Paulo: Cengage learning.

Itaqui, L., \& Felippi, G. (2017). Cinema, psicologia e homoafetividade: reflexões das cenas do contemporâneo. In L. P. Ribeiro, Família(s) e afetividade(s) (pp. 131-146). Rio de Janeiro: Gramma.

Jesus, J. G. (2012). Orientações sobre identidade de gênero: conceitos e termos ( $2 \mathrm{a}$ ed.). Brasília. Recuperado de http://www. diversidadesexual.com.br/wp-content/uploads/2013/04/ G\%C3\%8ANERO-CONCEITOS-E-TERMOS.pdf

Kuenzer, A. Z. (2007). Da dualidade assumida à dualidade negada: o discurso da flexibilização justifica a inclusão excludente. Educação \& Sociedade, 28(10), 1153-1178. Recuperado de http://www.scielo.br/pdf/es/v28n100/a2428100.pdf. doi: 10.1590/S0101-73302007000300024

Lanz, L. (2014). O corpo da roupa: A pessoa transgênera entre a transgressão e a conformidade com as normas de gênero (Dissertação de Mestrado), Universidade Federal do Paraná, Curitiba, PR, Brasil. Recuperado de https://acervodigital.ufpr.br/handle/1884/36800

Laqueur, T. W. (2001). Inventando o sexo: corpo e gênero dos gregos a Freud. Rio de Janeiro: Relume Dumará. 
Lessa, S. (2015). Para Compreender a Ontologia de Lukács (4a ed.). São Paulo: Instituto Lukács.

Manzini, E. J. (2004). Entrevista Semi-estruturada: análise de objetivos e de roteiros. In Anais do Seminário Internacional sobre Pesquisa e Estudos Qualitativos, Bauru, SP, Brasil, 2. Recuperado de https://www.marilia.unesp.br/Home/Instituicao/Docentes/EduardoManzini/Manzini_2004_entrevista_semi-estruturada.pdf

Marx, K. (2017). O Capital - Livro I (2a ed.). São Paulo: Boitempo.

Nogueira, F. J. S., \& León, A. G. (2012). "Trabalhadas no feminino": um estudo sobre corpo, desejo e prostituição travesti em Fortaleza-CE. Revista Latinoamericana de Estudios sobre Cuerpos, Emociones y Sociedad, 8(4), 55-67.

Nogueira, S. N. B. (2017). Travestis no limbo: violações de direitos humanos. In S. N. B. Nogueira, T. A. Araújo, \& E. A. Cabral., Dossiê: a geografia dos corpos das pessoas trans (pp. 37-41). Rede Trans Brasil.

Oliva, T. D. (2015). Minorias sexuais e os limites da liberdade de expressão: o discurso do ódio e a segregação dos indivíduos LGBT no Brasil. Curitiba: Juruá.

Peres, W. S. (2012). Travestilidades nômades: a explosão dos binarismos e a emergência queering. Revista Estudos Feministas, 20(2), 539-547. Recuperado de https://periodicos.ufsc. br/index.php/ref/article/view/S0104-026X2012000200014. doi: 10.1590/S0104-026X2012000200014

Piscitelli, A. (2008). Interseccionalidades, categorias de articulação e experiências de migrantes brasileiras. Sociedade e Cultura, 11(2), 263-274. doi: 10.5216/sec.v11i2.5247

Resolução CFM no 1.482 /1997. Recuperado de: http://www.portalmedico.org.br/resolucoes/cfm/1997/1482_1997.htm

Resolução CFM n $n^{\circ}$ 1.955/2010. Dispõe sobre a cirurgia de transgenitalismo e revoga a Resolução CFM n 1.652/02. (Publicada no Diário Oficial da União; Poder Executivo, Brasília-DF, n. 232, 2 dez.2002. Seção 1, p.80/81). Recuperado de http://www.portalmedico.org.br/resolucoes/ cfm/2010/1955_2010.htm

Ribeiro, L. P., Vilanni, F. B., Silva, I. P., \& Alexandre, P. T. S. (2019). Nós sofremos violência todo dia!: Representações sociais e vivências de violência para pessoas transgêneras. IQUAL. Revista de Género e Igualdad, 2, 22-40. Recuperado de https://revistas.um.es/iqual/article/ view/327291/257401. doi: 10.6018/iQual.327291

Ribeiro, L. P., \& Resende, C. C.. (2017). Breve ensaio sobre o conceito de vulnerabilidade social: exclusão social, trabalho, democracia e empoderamento. Percurso Acadêmico, 7(14), 378-400. Recuperado de http://periodicos.pucminas. br/index.php/percursoacademico/article/view/16191. doi: 10.5752/P.2236-0603.2017v7n14p378-400
Rocha, Â., Ban, G., \& Valenga, R. (2017). Brasil é o país que mais mata travestis e transexuais no mundo [Internet]. Reuperado de http://periodico.jor.br/index.php/direitos-humanos/669-brasil-e-o-pais-que-mais-mata-travestis-e-transexuais-no-mundo

Rostagnol, S. (2000). Regulamentação: controle social ou dignidade do/ no trabalho? In M. Benedetti, \& A. Fábregas-Martinez (Orgs.), Na Batalha: sexualidade, identidade e poder no universo da prostituição. Porto Alegre: Dacasa, Palmarica.

Transgender Europe. (2017). TMM Update Trans Day of Visibility 2017 -Press Release. [Internet]. Recuperado de http:// transrespect.org/en/tdov-2017-tmm-update/

Silva, L. B. (2013). Modos de vida e pertencimento: reflexões sobre as relações e significações no território prostitucional. Anais do Seminário Internacional Fazendo Gênero 10, Florianópolis, SC, Brasil. Recuperado de http:// www.fg2013.wwc2017.eventos.dype.com.br/resources/ anais/20/1373070041_ARQUIVO_resumocompleto.pdf

Simakawa, V. V. (2015). Por inflexões decoloniais de corpos e identidades de gênero inconformes: uma análise autoetnográfica da cisgeneridade como normatividade (Dissertação de mestrado). Programa Multidisciplinar de Pós-Graduação em Cultura e Sociedade, Instituto de Humanidades, Artes e Ciências Professor Milton Santos, Universidade Federal da Bahia, Salvador, BA, Brasil. Recuperado de https://repositorio.ufba.br/ri/handle/ri/19685

Zanin, H. S., Ferreira, L. S., \& Ribeiro, L. P. (2019). Ingresso e Permanência no Trabalho e Emprego por Sujeitos LGBT+ em Belo Horizonte, Brasil. Id on Line Revista Multidisciplinar Psicologia, 13(44), 460-474. Recuperado de https://idonline. emnuvens.com.br/id/article/view/1624. doi: 10.14295/ idonline.v13i44.1624 